\title{
Assessment of Mother's Knowledge and Attitude Regarding Newborn Care at Public Hospitals in Kirkuk City
}

\author{
Hewa Shareef Azeez ${ }^{1}$, Bahar Nasradeen Majeed ${ }^{2}$ \\ ${ }^{1}$ M.Sc. Student, Department of Pediatric Nursing/College of Nursing, University of Sulaimani, \\ ${ }^{2}$ Lecturer, Dr., Department of Pediatric Nursing/College of Nursing, University of Sulaimani
}

\begin{abstract}
Objectives: To assess mother's knowledge and attitude regarding newborn care and find out the relationship between socio-demographic characteristics with the mother's knowledge and attitudes in Kirkuk city.

Methodology: Quantitative approach, cross sectional study design has been carried out in Kirkuk public hospitals from period of 9 August 2016 to 26 May 2018. A non -probability/convenient sampling technique was applied in the present study. Taken those mothers whose babies age are less than one month in three public hospitals of Kirkuk city.

The questionnaire was designed and constructed by the researcher to measure the variables underlying the present study, which consists of three sections, with reliability $(0.830)$ was measured by using Cronbach's alpha formula.

Results: The findings demonstrate that overall knowledge mean were 1.49, which mean fair level of knowledge. Regarding to the attitudes result indicates that $88 \%$ of the sample had positive attitude. The findings indicate significant relationship between knowledge of mother with both variables type of family at $p$ value and educational level and attendance to antenatal care while the relationship highly significant relationship received any information on newborn care during this pregnancy, mother age, occupation and rank of neonate in family. Concerning mother's attitudes there is a significant relationship between attitude of mother and received anti tetanus vaccine, rank of neonate in family and occupation.
\end{abstract}

Keywords: Mother's Knowledge, Newborn Care, Public Hospitals, Kirkuk City.

\section{Introduction}

Newborn is considered to be tiny and powerless, completely dependent on others for life within one minute of birth the normal newborn adapts from a dependent fetal existence to an independent one; capable of breathing and carrying on life process. The first hours are crucial because multiple organ systems are making the transition from intrauterine to extrauterine functions ${ }^{1}$. There are many causes of neonatal deaths. Complications during pregnancy, the poor health condition of the mother, lack of proper care during pregnancy, filthy conditions during delivery, critical conditions after birth and improper newborn care are some of the major causes of neonatal mortality. Children also die due to premature birth, severe malformation, obstetric complications, or because of infections caused by harmful practices at home. It is estimated that around one percent of infants being born with major congenital anomalies around the world and it is found more common in developing and poor developed countries than in developed countries ${ }^{1}$. Globally 4 million newborns die every year before they reach the age of one month. Out of the 1.5 million newborn die in four countries of South Asia. Approximately 3.4 million newborns die within the first week of life. Of these deaths, $66 \%$ occur during the 1 st 24 hours. Late death i.e.; after 24 hours, still occur $34 \%$ and may be prevented if mothers have knowledge about newborn care including dangers sign of newborn. The care the newborn depends a lot on the knowledge, skills, and attitude of the mother. The prim gravida mothers are supposed to be lacking in knowledge and attitude of newborn care ${ }^{2}$. The majority of newborn deaths take 
place in developing countries where access to health care is low. Most of these newborns die at home, without skilled care that could greatly increase their chances for survival. Skilled health care during pregnancy, child and in the postnatal (immediately following birth) period prevents complications for mother and newborn and allows for early detection and management of problems ${ }^{3}$.

\section{Methodology}

Design of the Study: Quantitative approach, descriptive study design has been carried out in Kirkuk public hospitals from period of 9 August 2016 to 26 April 2018. To assess the mother's knowledge and attitude regarding newborn care at public hospitals in Kirkuk city.

Setting of Study: The study was carried out in pediatric wards of three governmental hospitals in Kirkuk city (Azadi Teaching Hospital, Kirkuk General Hospital and Pediatric Hospital).

1. Azadi Teaching Hospital: Azadi teaching hospitalis considered as one of the major hospital which is established in 1983 and located to the north of the city. the building consists of (6) floors with (400) beds, pediatric wards consist of (64) beds.

2. Kirkuk General Hospital: Kirkuk general hospital is one of the oldest hospitals in Kirkuk city. The building is constructed in 1945 and located in the center of the city. It consists of many departments and has (350) beds, pediatric department is one of them which includes (20) beds.

3. Pediatric Hospital: Pediatric hospital which is located at the center of Kirkuk city, established in 1972, it is a special hospital for pediatric that includes 120 beds, which offers the services exclusively to children.

Sampling of the Study: A non -probability/ convenient sampling technique was applied in the present study. Taken those mothers who is their baby's age with less than one month in governmental hospitals of Kirkuk city. Two hundred forty mothers were constituted the study sample that they were recruited from (Azadi Teaching Hospital 80 mothers, Kirkuk General Hospital 80 mothers, Pediatric Hospital 80 mothers).

\section{Inclusion Criteria:}

$>$ Mother's of neonates age (0-28) days.

$>$ Mother's agree to participate in the study.

\section{Exclusion Criteria:}

Mother's of neonates died at the birth.

Mother's of babies with congenital anomalies.

Mother's are unconscious or mentally retarded.

Tools of Data Collection: In order to collect the proper information study, the questionnaire was designed and constructed by the researcher to measure the variables underlying the present study.

Patterns of Means of Scores Calculation: The total mean scoring for section two (knowledge questions) in each domain regarding to the following patterns:

1. The mean of each item if equal to (1.00-1.333) indicate poor level of knowledge.

2. The mean of each item if equal to (1.334-1.666) indicate fair level of knowledge.

3. The mean of each item if equal to (1.667-2.00) indicate good level of knowledge.

The total mean scoring for section three (attitude questions) regarding to the following patterns:

1. The mean of each item if equal to (1.00-2.00) indicate negative attitude.

2. The mean of each item if equal to (2.01-3.00) indicate positive attitude.

Pilot Study: A pilot study was conducted on (20) mothers in Azadi teaching hospital, Kirkuk general hospital and Pediatric hospital. It was carried out from 6-10 June in 2016. The pilot study sample were excluded from the study sample. Objectives of the pilot study include the following:

1. To identify the barriers that may face the researcher during data collection.

2. To examine the cooperation of study sample

3. To estimate the time required for each mother interview

4. To determine the stability and clarity of questionnaire or study tool

Before data collection began, pilot test was conducted to assess the general of administering the instrument, and conciseness of the questions. 


\section{Reliability and Validity:}

Validity: Once the questionnaire for the study is prepared it must be validated. This validation aims at assessing questionnaire according comprehension, relevance to their intended topics, effectiveness in providing useful information and the degree to which the questions are interpreted and understood by different individuals. Content validity of the instrument was determined through the use of panels (15) experts (Appendix A) to investigate the clarity of the questionnaire, the mean of expertise years of experience were 11 years. Relevancy and adequacy of the questionnaire are required in order to achieve the present study objectives. Their responses indicated that all of them had agreed upon the questionnaire content clarity, relevancy, and adequacy. Then the questionnaire was considered valid after taking into consideration their suggestions and recommendations for modification.

Reliability: To test the questioner reliability, internal consistency was measured using Cronbach's alpha formula on twenty nurses who is excluded from the original study sample. The result of pilot study was (0.830), that indicate reliable of the questionnaire and it is acceptable and adequately to measure and assessment of these mother's knowledge. The following formula was used for reliability estimate of stability of a measure (polite and hungler, 1999).

$$
\begin{aligned}
& r=n \sum x y-\left(\sum x\right)\left(\sum y\right) / \sqrt{ }\left[\left(n \sum x,-\left(\sum x\right),\right]\left[n \sum y,-\left(\sum y\right) \prime\right]\right. \\
& \mathrm{r}=\text { the correlation coefficient for variable } \mathrm{x} \text { and } \mathrm{y} \\
& \mathrm{n}=\text { number of sample } \\
& \mathrm{x}=\text { an individual score for variable } \mathrm{x} \\
& \mathrm{Y}=\text { an individual score for variable } \mathrm{y} \\
& \sum=\text { the summation of. }
\end{aligned}
$$

Method of Data Collection: The interviews technique was done by the researcher with each selected mothers those stayed at public hospital mentioned above to get their responses and to clarify the items mentioned in the questionnaire form of the study.

Each interview took approximately (10-20) minutes with each mother. All participants were informed that the information will be kept confidential and used just for a scientific purpose. The data collected for the period between 9 August to 5 November 2016.

Statistical Analysis: All the data were coded and entered to the computer using SPSS software version 23.

\section{Results}

Table (1) raveled that more than half of samples which accounts $51.3 \%$ their babies age between (1-7) days, it means they are newborn baby and they need special newborn care, followed by both age groups (814) days and (15-21) days which accounts $20.0 \%$ for each group, the fewest percentages of samples $8.8 \%$ their babies age between (22-28) days. Regarding the neonate's birth order or rank of neonate in family majority of sample their babies were first birth order or/first ranking in the family which accounts $39.6 \%$, third and second birth order records, $25.4 \%$ and $23.8 \%$ respectively. Only few percentage of sample $11.3 \%$ their babies are fourth or more birth order, recently family size become small, although majority of samples their babies was first birth order, it means they have no experience about how to take care of newborn baby. It is worth to mention that more than half of samples $57.9 \%$ visits primary health care center four or more time, and very small percentages which accounts $5.8 \%$ have no visits (PHCC), this is good indicator for that our samples have commitment to attending (PHCC) for receiving information about newborn care and this important issue related to pre, post, and antenatal care, vast majority of samples $97.9 \%$ were received anti tetanus vaccine, and the rest of sample not received anti tetanus vaccine.

Table (1) Distribution of the sample according to antenatal and birth history

\begin{tabular}{|l|l|c|c|}
\hline Variables & Frequency & Percentage \\
\hline \multirow{4}{*}{ Age of neonate } & $1-7$ days & 123 & 51.25 \\
\cline { 2 - 4 } & $8-14$ days & 48 & 20.0 \\
\cline { 2 - 4 } & $15-21$ days & 48 & 20.0 \\
\cline { 2 - 4 } & $22-28$ days & 21 & 8.75 \\
\hline
\end{tabular}




\begin{tabular}{|l|l|c|c|}
\hline \multicolumn{2}{|l|}{ Variables } & Frequency & Percentage \\
\hline \multirow{4}{*}{ Rank of neonate in family } & First & 95 & 39.6 \\
\cline { 2 - 4 } & Second & 57 & 23.75 \\
\cline { 2 - 4 } & Third & 61 & 25.4 \\
\cline { 2 - 4 } & > fourth & 14 & 11.25 \\
\hline \multirow{4}{*}{$\begin{array}{l}\text { Previous attendance to antenatal care or (PHCC) } \\
\text { during this pregnancy }\end{array}$} & No visits & 1 visits & 28.8 \\
\cline { 2 - 4 } & 2 visits & 24 & 11.7 \\
\cline { 2 - 4 } & 3 visits & 35 & 10.0 \\
\cline { 2 - 4 } & $>4$ visits & 139 & 14.6 \\
\hline Received anti tetanus vaccine & Yes & 235 & 57.9 \\
\hline
\end{tabular}

Table (2) Distribution of the sample in terms of receiving information on newborn care.

\begin{tabular}{|l|l|c|c|}
\hline \multicolumn{2}{|l|}{ Variables } & Frequency & Percentage \\
\hline \multirow{2}{*}{$\begin{array}{l}\text { Received any information on newborn care during } \\
\text { this pregnancy }\end{array}$} & Yes & 172 & 71.7 \\
\cline { 2 - 4 } & No & 68 & 28.3 \\
\hline \multirow{2}{*}{$\begin{array}{l}\text { Received any information newborn care information } \\
\text { since delivery/at hospital }\end{array}$} & Yes & 96 & 40.0 \\
\cline { 2 - 4 } & No & 144 & 60.0 \\
\hline
\end{tabular}

Table (2) this table demonstrates that the highest percentages of samples which records $71.7 \%$ were receiving information on newborn care during this pregnancy, but only $40.0 \%$ of them receiving newborn care information since delivery/at hospital, while more than half $60.0 \%$ of samples will not receive any information about newborn care.

Table (3) Distribution of sample according to mother's level of knowledge in all five domains.

\begin{tabular}{|c|c|c|c|c|c|c|c|c|c|}
\hline & \multirow{2}{*}{$\begin{array}{c}\text { Knowledge } \\
\text { Domains }\end{array}$} & \multicolumn{2}{|c|}{ Poor Level } & \multicolumn{2}{|c|}{ Fair Level } & \multicolumn{2}{|c|}{ Good Level } & \multirow{2}{*}{$\begin{array}{l}\text { Total } \\
\text { Mean }\end{array}$} & \multirow{2}{*}{ Level } \\
\hline & & f & $\%$ & f & $\%$ & f & $\%$ & & \\
\hline 1 & D 1 & 21 & 8.8 & 130 & 54.2 & 89 & 37.1 & 1.59 & Fair \\
\hline 2 & D 2 & 28 & 11.7 & 152 & 63.3 & 60 & 25.0 & 1.53 & Fair \\
\hline 3 & D 3 & 83 & 34.6 & 124 & 51.7 & 33 & 13.8 & 1.51 & Fair \\
\hline 4 & D 4 & 71 & 29.6 & 57 & 23.8 & 112 & 46.7 & 1.56 & Fair \\
\hline 5 & D 5 & 83 & 34.6 & 118 & 49.2 & 39 & 16.3 & 1.45 & Fair \\
\hline \multicolumn{2}{|c|}{ Knowledge Grand total } & 16 & 6.7 & 200 & 83.3 & 24 & 10.0 & 1.49 & Fair \\
\hline
\end{tabular}

D 1-Mother's knowledge on newborn care for Breastfeeding.

D 2-Mother's knowledge on newborn care for Immunization.

D 3-Mother's knowledge on newborn care for Umbilical Cord care.

D 4-Mother's knowledge on newborn care for Thermoregulation.

D 5-Mother's knowledge on newborn care for Danger signs.

$f$-Frequency.

$\%$-Percentage.

The findings in the above Table (3) explore that fair level of knowledge of the sample records the highest percentages in all domains one, two, three, and five which accounts $54.2 \%, 63.3 \%, 51.7 \%$, and $49.2 \%$ respectively, while only in domain number four which deals with knowledge about thermoregulation the good level of knowledge records the highest percentages which accounts $46.7 \%$.Regarding the total mean of score, in all 
five domains total mean scores were in fair levels which accounts $1.59,1.53,1.51,1.56$, and 1.45 and total mean score in general were 1.49 which is also fair level of knowledge. It is worth mentioning that domain number one which deals with knowledge about breastfeeding records' the highest mean score 1.59 followed by domain number four 1.56 which deals with knowledge about thermoregulation, then domains two, and three records $1.53,1.51$ respectively. While the lowest mean score was record in domain five. This indicated to that mother's level of knowledge in general was not bad and it was in fair level, and they need more knowledge about newborn care. In the study conducted among mother's knowledge on newborn care for breastfeeding. And they found more than three quarter have a good knowledge this study incompatible with our presentstudy. Related to the second domain, the present study is supported by a study carried out in Ethiopiaby Birhanu et al., (2016), who found that average knowledge level regarding immunization.

\section{Table (4) Distribution of sample according to relationship between mother knowledge and some socio demographic characteristics.}

\begin{tabular}{|c|c|c|c|}
\hline Variables & ANOVA & P Value & CS \\
\hline Mother age & 2.749 & .000 & HS \\
\hline Residence & 2.996 & .052 & NS \\
\hline Occupation & 13.232 & .000 & HS \\
\hline Religion & 2.826 & .061 & NS \\
\hline Economic & 2.188 & .114 & NS \\
\hline Educational level & 3.427 & .005 & Sig. \\
\hline Age of neonate & .359 & .782 & NS \\
\hline Rank of neonate in family & 8.438 & .000 & HS \\
\hline $\begin{array}{l}\text { Previous attendance to } \\
\text { antenatal care or (PHCC) } \\
\text { during this pregnancy }\end{array}$ & 3.400 & .010 & Sig. \\
\hline
\end{tabular}

ANOVA (Analysis of Variance), Comparative Significance CS: Highly significant (HS) at $<0.01$, Significant (S) at $p \leq 0.05$, Not significant (NS) at $\mathrm{p} \geq 0.05$.

Table (4) The findings in this table shows that high significant relationship were found between each of mother age, occupation and rank of neonate in family at $\mathrm{p}<0.001$ respectively, as explore in Table (4-1) majority of the samples their age ranged between (1630) years old, so they are between late adolescent and young adults stage of life which is a suitable period for receiving knowledge and learning, in the same Table (41) more than half of sample were housewife and this is a good indicator for that the mothers in our sample have enough time for taking care of their newborn babies .

Although one quarter of sample was graduated from institute and college, most of the sample were housewife and not employed, this is a good indicator to that the mothers in this study had enough time for taking care for their babies and receiving knowledge and information about newborn care, regarding neonate's birth order, most of neonates in the present study were first order, so the mothers have more interested to learning what is important regarded baby care.

Significant relations were found between mother's level of educational and level of knowledge $p$ value 0.005 , it is indicated to that high level of education means good level of knowledge. Also, significant relationship was found between of mother's level of knowledge and mothers whom visiting to PHCC during this pregnancy, at $p$ value 0.010 , one objective to $\mathrm{PHCC}$ is to raise mothers or caregivers level of knowledge and attitude about newborn care.

It is worth mentioning that no significant relationship were found between samples residency, religion, economic states, and age of neonate with mother's level of knowledge.

The finding in the present study agrees with the results of previous study done by ${ }^{11}$ that there is significant relationship between knowledge of mother and educational level and non-significant with residence, while it disagrees with our study which found that there is non-significant relationship between knowledge of mother and their (mother age, occupation).

The result in the present study agrees with the results in the previous study done by Vinod and Anuchithra, 2014 which found that there is non-significant relationship betweennewborn care among prime mother and (Religion, Economic, Age of neonate). 
Table (5) Distribution of sample according to relationship between mother's knowledge and their (type of family, type of delivery, received anti tetanus vaccine, received any information on newborn care during this pregnancy and received any newborn care information since delivery/at hospital).

\begin{tabular}{|c|c|c|c|c|c|c|}
\hline \multicolumn{2}{|r|}{ Knowledge } & Mean & SD & $t$-test & $p$ value & \\
\hline \multirow{2}{*}{ Type of family } & Nuclear & 1.50 & .113 & \multirow{2}{*}{2.85} & \multirow{2}{*}{.005} & \multirow{2}{*}{ Sig. } \\
\hline & Joint & 1.46 & .099 & & & \\
\hline \multirow{2}{*}{ Type of delivery } & Normal vaginal delivery & 1.50 & .111 & \multirow{2}{*}{1.26} & \multirow{2}{*}{.209} & \multirow{2}{*}{ NS } \\
\hline & Caesarean section & 1.48 & .107 & & & \\
\hline \multirow{2}{*}{ Received antitetanus vaccine } & Yes & 1.49 & .109 & \multirow{2}{*}{1.88} & \multirow{2}{*}{.129} & \multirow{2}{*}{ NS } \\
\hline & No & 1.41 & .100 & & & \\
\hline \multirow{2}{*}{$\begin{array}{l}\text { Received any information on newborn } \\
\text { care during this pregnancy }\end{array}$} & Yes & 1.51 & .114 & \multirow{2}{*}{5.02} & \multirow{2}{*}{.000} & \multirow{2}{*}{$\mathrm{HS}^{*}$} \\
\hline & No & 1.44 & .072 & & & \\
\hline \multirow{2}{*}{$\begin{array}{l}\text { Received any newborn care } \\
\text { information since delivery/at hospital }\end{array}$} & Yes & 1.49 & .102 & \multirow{2}{*}{-.387} & \multirow{2}{*}{.699} & \multirow{2}{*}{ NS } \\
\hline & No & 1.49 & .114 & & & \\
\hline
\end{tabular}

(*) Highly significant (HS) at $<0.01$, Significant (S) at $\mathrm{p} \leq 0.05$, Not significant (NS) at $\mathrm{p} \geq 0.05$.

The above table demonstrates that high significant relationships were found between respondents' knowledge and who receiving information on newborn care during this pregnancy $\mathrm{p}$ value $<0.01$ without doubt receiving information specialty at time of pregnancy affect the level of knowledge of mothers regarding newborn care.

Significant relationships were between the mother level of knowledge and the type of family, more than half of samples have nuclear family which indicated the caregiver dependent on her-self for caring of babies. In addition to that, no significant relationships were found between the type of delivery, received ATS, received any newborn care information since delivery/at hospital, $\mathrm{p}$ value $\geq 0.05$ which records $0.209,0.129$, and 0.699 respectively. Bofarraj, M. (2011), did a study entitled “ Knowledge, attitude and practices of mothers regarding immunization of infants and preschool children at AlBeida City, Libya “. This study agrees with our results that found there is a significant relationship between the knowledge of mother and the type of family while disagrees with our results among the relationship between the knowledge of mother and the type of delivery that found a significant relationship between them, also that agrees with our result that found nonsignificant relationships between the knowledge of mother and the (Received antitetanus vaccine). A study was done by Timilsina and Dhakal, 2015 to examine the knowledge on postnatal care among postnatal mothers this study disagrees with our present study results which found non-significant relationship between the knowledge of mother and received any information on newborn care during this pregnancy, while it agrees with our results among relationship between knowledge of mother and received any newborn care information since delivery/at hospital. According to the researcher point of view, children are the future of any nation. It is well established that the welfare of a child and his future are totally dependent upon the care and attention bestowed upon him before and after birth. The care of children had always traditionally been the forte of mothers irrespective of education.

\section{Conclusions}

The main conclusions in this study are:-More than half of the sample mother age ranged between (16-20) years and (21-25) years old, and proportion of urban record higher percentage. More than half of the sample were housewives and highest percentage of the sample gain institute or college degree. According to economic status most of them have a sufficient. More than half of the sample were nuclear family. Majority of the sample their age of neonate ranged between (1-7) days. Significant relationship was found between knowledge of mother and the type of family, educational level and previous attendance to antenatal care or primary health 
care center during this pregnancy. Non-significant relationship was found between knowledge of mother and the type of delivery, received anti tetanus vaccine, received any newborn care information since delivery/ at hospital, residence, religion, economic and age of neonate. Significant relationship was found between attitudes of mother and their received anti tetanus vaccine, occupation and rank of neonate in family. while remaining variable were non-significant.

Financial Disclosure: There is no financial disclosure.

Conflict of Interest: None to declare.

Ethical Clearance: All experimental protocols were approved under the University of Sulaimaniand all experiments were carried out in accordance with approved guidelines.

\section{References}

1. Mohamed AA. Knowledge, Attitude and Practice of Diabetes Control among Patients, Khartoum Teaching Hospital. International Journal of Science and Research (IJSR).2016; 5: 47-48.

2. NasirN, Amran Y, Nakamura Y. Changing Knowledge and Practices of Mothers on Newborn Care through Mother Class: An Intervention Study in Indonesia. Journal of Tropical Pediatrics. 2017; 63: 441-442.

3. Akseer N, Lawn J, Keenan W. Ending preventable newborn deaths in a generation. International Journal of Gynecology \& Obstetrics. 2015; 131:43.

4. Chaudhari S, Virmani S. Knowledge and attitude of postnatal mothers towards neonatal care in a rural area of Maharashtra, India. International Journal of Reproduction, Contraception, Obstetrics and Gynecology. 2016; 5: 1883-1885.

5. Chishtin A, Alam S, Kiessling, S. Kidney and Urinary Tract Diseases in the Newborn. Berlin, Heidelberg: Springer Berlin Heidelberg. 2014;1101-1102.

6. EsanAJ. Hemolytic Disorders of the Newborn, Current Method of Diagnosis and Treatment: A Review Study. Hematology, Blood Transfusion \& Disorders, 2016; 3: 18.

7. Faisal S, Ali S, Roshan, E, Jamal S. Alcohol Application Versus Natural Drying of Umbilical Cord. Saudi Journal of Medical and Pharmaceutical Sciences, 2006; 6: 4-6.

8. Firth M, Shewen, P, Hodgins D. Passive and active components of neonatal innate immune defenses. Animal Health Research Reviews. 2005; 6: 145146.

9. NasirN, Amran Y, Nakamura Y. Changing Knowledge and Practices of Mothers on Newborn Care through Mother Class: An Intervention Study in Indonesia. Journal of Tropical Pediatrics. 2017; 63: 441-442.

10. Pirone C, Quirke J, Priestap H, Lee D. Animal Pigment Bilirubin Discovered in Plants. Journal of the American Chemical Society, Volume 131, Issue 8, pp.2830.

11. Sharafi R, Esmaeel H. knowledge assessment of neonatal care among postnatal mothers. Iranian Journal of Neonatology. 2013; 4: 29-30. 